\title{
Role of physical medicine for cancer rehabilita- tion and return to work under the premise of the "Wiedereingliederungsteilzeitgesetz"
}

\author{
Fadime Cenik · Bruno Mähr · Stefano Palma · Mohammad Keilani · Thomas Nowotny · Richard Crevenna $(\mathbb{D}$
}

Received: 16 February 2019 / Accepted: 24 April 2019 / Published online: 13 May 2019

(C) The Author(s) 2019

\begin{abstract}
Summary
Background With the intention of enabling people a phased return to work after long-term sick leave the so-called "Wiedereingliederungsteilzeitgesetz" (WIETZ) was implemented in Austria on 1 July 2017. Methods To explore the overall awareness about the WIETZ and the value of physical modalities together with further supporting measures in return to work of cancer survivors, a survey by using a self-constructed questionnaire was performed in 30 experts 6 months after the WIETZ came into force.

Results The awareness of Austrian specialists regarding the WIETZ seems to be excellent. Regarding expert opinions, return to work in cancer survivors is notable hampered in workplaces with great physical stress even in times of the WIETZ, whereas for professions in offices and banks it is easier to return to work, with and without WIETZ. The highest impact on return to work seems to be due to exercise, as an intervention of the field of physical medicine and rehabilitation to improve sensorimotor functions and to increase endurance capacity as well as muscular strength.

Conclusion Early information about cancer rehabilitation and the WIETZ seems to be necessary to facilitate return to work of cancer survivors. Furthermore, exercise interventions seem to be the most important measures from the field of physical medicine and rehabilitation.
\end{abstract}

\footnotetext{
F. Cenik · S. Palma · M. Keilani · T. Nowotny ·

Univ. Prof. Dr. R. Crevenna, MBA, MSc ( $\varangle)$

Department of Physical Medicine, Rehabilitation and

Occupational Medicine, Medical University of Vienna,

Währinger Gürtel 18-20, 1090 Vienna, Austria

richard.crevenna@meduniwien.ac.at

B. Mähr

Rosalienhof, Bad Tatzmannsdorf, Burgenland, Austria
}

Keywords Workability · Part-time reintegration • Exercise · Experts' survey · Cancer

\section{Introduction}

Modern cancer care with increasing survival rates puts the focus on return to work in the cancer survivorship. Cancer rehabilitation has a key role in improving patients' quality of life, functional performance and participation. These factors have a high impact on return to work in cancer survivors by increasing ability to work, social participation and integrating patients into their normal life. Within this framework, patient-centered programs are deployed to help improving health care efficiency, identifying preferences and values of patients and their families and to help prioritizing goal-concordant care to reduce cancer-related symptoms and cancer treatment-related side effects [1-7].

Approximately $35 \%$ of all cancer patients are aged between 15 and 65 years [8-10], whereby approximately two thirds survive the disease (in Europe and Austria, [10]) and in further consequence one third of them finally become unemployed [6, 8-11]. Given the fact that ability to work has existential importance, cancer survivors show a high motivation for return to work $[6,8,9,11]$. Multidisciplinary programs seem to offer a bridge to return to work $[6,8,9,11]$, especially reconditioning therapies, namely exercise interventions, have been shown to be effective methods in cancer rehabilitation [1, 2, 12-14].

With the intention of enabling a phased return to work after long-term sick leave, a new law called the Part-time Reintegration Act (Wiedereingliederungsteilzeitgesetz, WIETZ) was implemented in Austria on 1 July 2017, which could be relevant especially in patients with cancer or mild mental diseases [1, 3, $5,15]$. This law stipulates a step by step approach 
Table 1 General data of participating experts $(N=30$; $48.5 \pm 10.4$ years)

\begin{tabular}{|c|c|c|}
\hline & Number & $\%$ \\
\hline $\mathrm{F}$ & 7 & 23.3 \\
\hline M & 23 & 76.7 \\
\hline n.s. & 0 & 0 \\
\hline V.e. in cancer rehab. & 22 & 73.3 \\
\hline No v.e. in cancer rehab. & 8 & 26.7 \\
\hline n.s. & 0 & 0 \\
\hline V.e. in physical med. & 16 & 53.3 \\
\hline No v.e. in physical med. & 14 & 46.7 \\
\hline n.s. & 0 & 0 \\
\hline V.e. in occupational med. & 12 & 40.0 \\
\hline No v.e. in occupational med. & 17 & 56.7 \\
\hline n.s. & 1 & 3 \\
\hline Know about WIETZ & 27 & 90.0 \\
\hline Do not know about WIETZ & 3 & 10.0 \\
\hline n.s. & 0 & 0 \\
\hline Awareness of key points about WIETZ & 26 & 86.7 \\
\hline No awareness of key points about WIETZ & 4 & 13.3 \\
\hline n.s. & 0 & 0 \\
\hline
\end{tabular}

in return to work by enabling fewer working hours (reduction of $25-50 \%$ ) for a predefined time but almost equal pay (compensation by social insurance) and under the condition that employers also agree [1, $3,5,15]$. With the aid of this measure, cancer survivors can return to work earlier or obtain workability in accordance with their physical and psychological conditions.

The aim of this pilot study was to examine the role of physical medicine in cancer rehabilitation and return to work under the premise of the WIETZ by using the methodological approach of an expert survey.

\section{Methods}

This pilot study was a survey with 30 experts from different fields of medicine (occupational medicine, physical medicine and rehabilitation, oncology, cardiology, radiology, sports science, psycho-oncology and nutrition science) and jurisprudence, which was performed to evaluate the role of physical medicine for cancer rehabilitation and return to work under the premise of the WIETZ, and took place as part of a masters thesis (for the field of medicine for organizations) of the corresponding author [16].

Experts were invited to fill in a self-constructed questionnaire, 6 months after the WIETZ came into force (end of December 2017) which consisted of general questions about demographic data and awareness of the WIETZ, and special questions about measures in cancer rehabilitation, return to work and further fields to facilitate workability in cancer survivors before and after the WIETZ. Furthermore, questions were asked about possible and impossible occupations for an optimal return to work after cancer rehabilitation before and after the WIETZ. The experts were asked to rank their answers from the best to the third best and from the unfavorable to third unfavorable, respectively.

\section{Statistical analysis}

Descriptive analysis was performed for demographic data, whereas remaining questions were analyzed quantitatively and qualitatively for the three best ranked and for all answers for each question.

\section{Results}

All invited experts $(N=30)$ agreed participation and the response rate was $100 \%$ within 2 weeks. Experts were from different fields of medicine (occupational medicine, physical medicine and rehabilitation, oncology, cardiology, radiology, sports science, psychooncology and nutrition science) and jurisprudence. Awareness about the topic of WIETZ was evaluated very well by the experts themselves. The age of the participants was between 29 and 68 years (mean 48.5a \pm 10.4 ). Demographic data are shown in Table 1.

Experts ranked some of their statements equally (ex equo). Therefore, there are more answers than expected. According to the experts, these are "of equal rank, depending on the indication", "depending on the tumor type, patients' status and complaints".

In Table 2 results from all special questions are presented. According to experts' opinions, the best supporting therapies to facilitate return to work in cancer patients could be from the field of physical medicine (active measures to increase strength and endurance capacity of cancer patients, such as training, physiotherapy, occupational therapy, etc.) and it's modalities (questions 1 and 2 in Table 2). An optimal phased return to work could be promoted best by the WIETZ or flexible working hours (question 3 in Table 2), especially for employees working in offices or banks (question 5 in Table 2). Office and bank employees had better opportunities to return to work before the implementation of the WIETZ (question 4 in Table 2). In contrast, employees with hard physical work seem to have great difficulties in returning to work, even after the WIETZ (question 6 in Table 2). Under the premises of the WIETZ, training has the highest impact on return to work of cancer survivors according to question 7 in Table 2. In addition, further physical therapies would be the best additional measures (question 8 in Table 2).

\section{Discussion}

Cancer survivors seem to have great difficulties in return to work [6, 8-11]. Approximately one third of cancer survivors in employable age are not able to work 


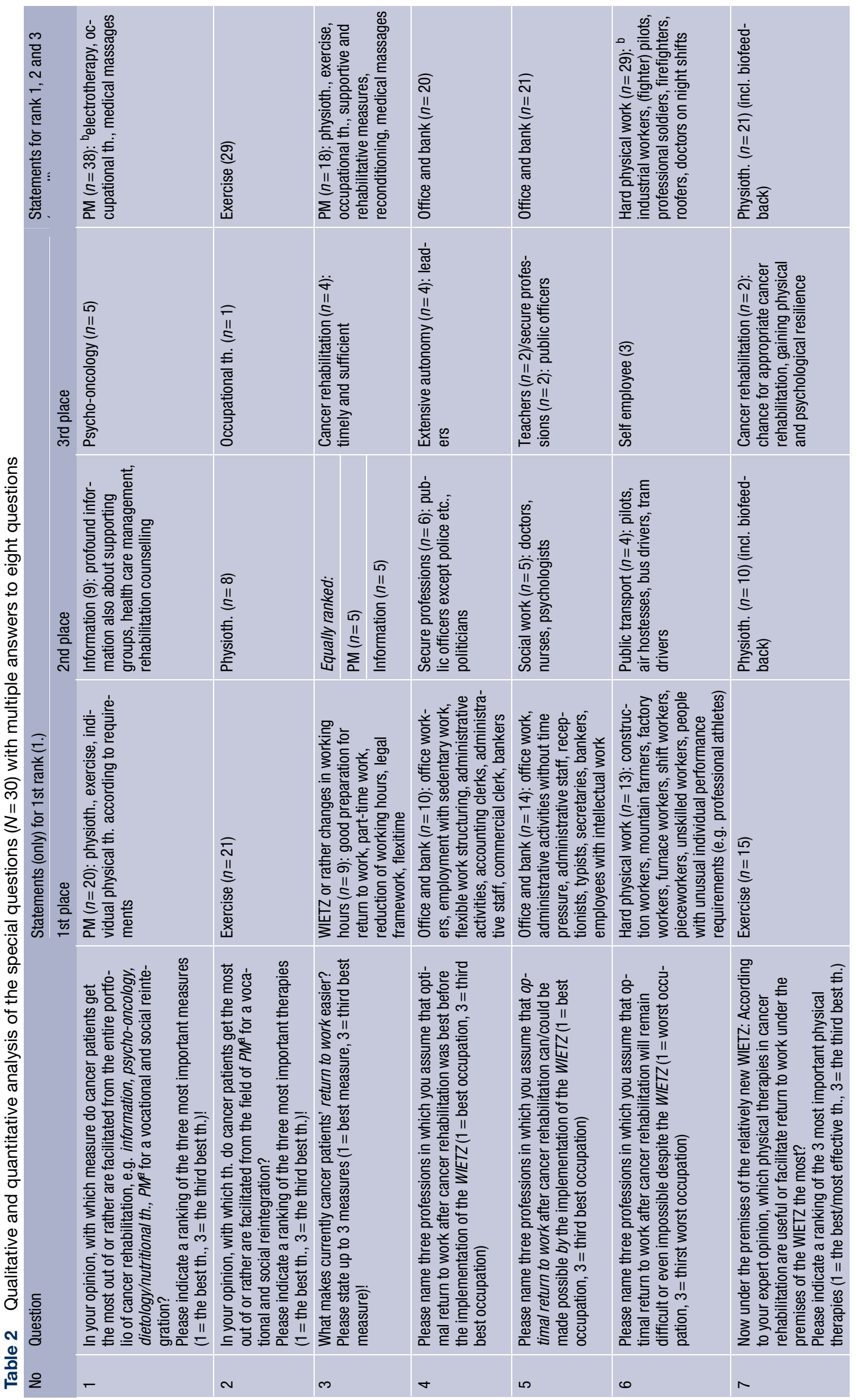




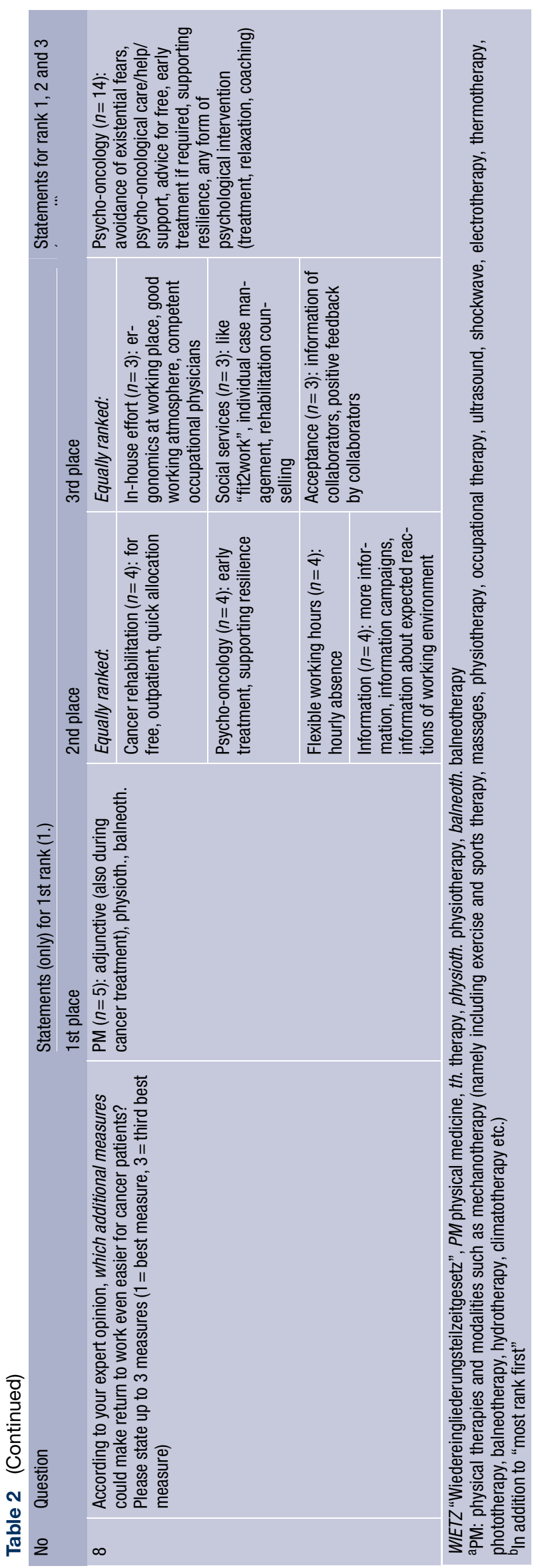

after cancer diagnosis or treatment [6, 8-11]. Care in multidisciplinary programs as in cancer rehabilitation seems to be a great support for cancer patients, especially in challenging issues such as workability $[6,8$, 9, 11].

Cancer rehabilitation is meanwhile an essential and integral part of cancer treatment, not least because of demonstrable effects in reduction of pain and other deficits and increase of functional performance, participation, quality of life, survival rate and workability [1-6]. Workability in cases of return to work facilitates dealing with cancer diseases, restores personal identity and social functioning and improves general health $[17,18]$. Thus, cancer rehabilitation is important to fight against the already high unemployment rate in cancer survivors [19-21].

In addition to cancer diagnosis, prognosis and therapy, type and intensity of work and duration of employment [22, 23], the limiting factors/barriers for a successful return to work could be ethnicity/race, education level and socioeconomic status [24-26], lack of adaptation of workplaces to the needs of disabled employees, feeling of being discriminated in the workplace despite high professional qualifications such as manager [20], as well as heavy physical stress, limited opportunities for decision-making and designing in the workplace and fixed-term employment contracts, etc. [27]. Ho et al. showed higher grades of depression, financial loss, fatigue, great physical symptoms and worse general condition in breast cancer patients with reduced workability [28]. By multidisciplinary interventions for reintegration an acceleration of return to work was shown in patients with (musculoskeletal) pain [29].

As a legal framework condition for a phased return to work after sickness absence, the WIETZ was implemented in Austria on 1 July 2017 [15]. Employers, patients and medical professions (as well as other medical stakeholders) need to be aware of the WIETZ for a realistic return to work management and for a well-functioning interface management system. The Department of Physical Medicine, Rehabilitation and Occupational Medicine of the Medical University of Vienna, as part of the establishment of cancer rehabilitation in Austria, had pioneering status alongside and in cooperation with other institutions and since then has focused on central themes in this field [1-7, 30-34]. In doing so, this survey with 30 specialists from the fields of cancer rehabilitation was performed by a self-constructed questionnaire 6 months after implementing the WIETZ in Austria. The key issues were to focus on experts' awareness and expertise as well as their opinions about implementation of the WIETZ in cancer patients. All invited experts agreed participation and the response rate was $100 \%$ within 2 weeks. Given this fact and taking into account the novelty of the law and the knowledge about its key points, specialists' awareness in return to work seem to be very high. This could be based on correspondent interests, 
events concerning this matter or the multidisciplinary cooperation.

One of the important interdisciplinary cooperation for cancer survivors is the so-called CCC-platform for side Eeffects management, supportive care and rehabilitation (CCC-SMSCR) at the Comprehensive Cancer Centre (CCC) of the Medical University of Vienna (General Hospital of Vienna, Austria). There, cancer patients dealing with various functional and symptomatic barriers are treated to increase functional capacity and quality of life, to reduce pain and its consequences, and also to give the opportunity to inform and for networking. In addition, workability, employment and return to work aspects are covered to support immediate return to daily living. By this means and depending on needs, objectives and abilities of each patient, a range of modalities and therapeutic options from the field of physical medicine and rehabilitation could be applied in all phases of medical care and cancer rehabilitation by basic directions of the International Classification of Functioning, Disability and Health (ICF) model. The therapeutic media mainly used are exercise (and recommendations for regular physical activity), physiotherapy and occupational therapy as active measures, of which success is highly dependent on patients' acceptance and adherence, and largely passive measures, such as (lymphatic) massage, electrotherapy (such as transcutaneous electrical nerve stimulation or galvanic baths), therapeutic ultrasound, shock-wave treatment or climatic and balneological treatment (such as hot packs, fango or mud).

With respect to the question of relevance of modules offered in the context of cancer rehabilitation (from the entire portfolio of cancer rehabilitation, question 1), the results of the expert survey clearly indicate that measures taken by physical medicine were considered to be fundamental to reintegrate cancer survivors. The most common best ranked physical measure before and also after implementation of the WIETZ was exercise (to increase strength, endurance capacity, flexibility and coordination). The need for these measures seems to increase even further as the long-term survival of cancer patients increases. In addition, the timely information of patients (before, during and after rehabilitation) about the WIETZ, legal status regarding dismissal/dismissal protection, possibilities for financial support and also the reference to cancer support groups, cancer aid as well as the course and outcome of this chronic illness seem to have high priority in return to work. Further important points to facilitate return to work for cancer survivors may be psycho-oncological care/help/ support for, e.g. supporting resilience and motivation, and avoidance of existential fears, and dietology/ nutritional therapy. Nevertheless, employees working in offices or banks seem to have best opportunities to return to work, under the premise of the WIETZ and also before implementation of it, whereas employees with hard physical work seem to have great difficulties in return to work, also despite the WIETZ. On the whole, the WIETZ or rather changes in working hours may be highly effective in supporting cancer survivors in returning to work step by step by ensuring more time for rehabilitation or resting time.

\section{Limitations}

This survey was performed by a self-constructed questionnaire. This approach appears to be well-established but could hide structural weakness. On the one hand, the prompt questioning 6 months after implementation of the WIETZ could be a limitation caused by less information about patients, who had experienced an optimal return to work under the premise of the WIETZ but on the other hand, high awareness was shown by the participants despite the novelty of this law. Another limitation could be the selection of the experts, who were directly or indirectly multidisciplinary cooperating partners; however, this limitation could be weak because of the important role of the participants and their comprehensive supervision all over Austria.

\section{Conclusion}

Cancer patients should be informed from the time of cancer diagnosis about cancer rehabilitation together with ways and possibilities of reintegration measures (workability, WIETZ) Furthermore, employed patients, their employers and physicians have to know about the importance of cancer rehabilitation, especially about physical options, such as exercise. Regularly performed exercise seems to have the highest impact on workability and return to work, which is an important issue for cancer patients. As many survivors are able and willing to work following a cancer diagnosis, future research should focus on rehabilitation and work reintegration concepts.

Acknowledgements The authors thank all experts for participating.

Funding Open access funding provided by Medical University of Vienna.

Conflict of interest F. Cenik, B. Mähr, S. Palma, M. Keilani, T. Nowotny, and R. Crevenna declare that they have no competing interests.

Open Access This article is distributed under the terms of the Creative Commons Attribution 4.0 International License (http://creativecommons.org/licenses/by/4.0/), which permits unrestricted use, distribution, and reproduction in any medium, provided you give appropriate credit to the original author(s) and the source, provide a link to the Creative Commons license, and indicate if changes were made. 


\section{References}

1. Crevenna R, Kainberger F, Wiltschke C, Marosi C, Wolzt M, Cenik F, et al. Cancer rehabilitation-Current trends and practices within an Austrian University Hospital Centre. Disabil Rehabil. 2018;17:1-6. https://doi.org/10.1080/ 09638288.2018.1514665.

2. Crevenna R. Cancer rehabilitation and palliative care-two important parts of comprehensive cancer care. Support Care Cancer. 2015;23(12):3407-8.

3. Crevenna R, editor. Physikalische Medizin und Rehabilitation - Ein Kurzlehrbuch. Vienna: Facultas/Maudrich; 2018.

4. Maehr B, Keilani M, Wiltschke C, Hassler M, Licht T, Marosi C, et al. Cancer rehabilitation in Austria-Aspects of physical medicine and rehabilitation. Wien Med Wochenschr. 2016;166(1/2):39-43.

5. Crevenna R. Return-to-work outcomes in cancer survivors. Support Care Cancer. 2017;25(10):3005-6.

6. Crevenna R, Wiltschke C, Marosi C, Mähr B, Hassler M, Licht T, et al. Onkologische Rehabilitation in Österreich als integriertes Modul im Kontinuum der Betreuung von PatientInnen mitmalignen Erkrankungen-Stichwort „Arbeitsfähigkeit/Return to work“. Phys Med Rehabil Kurortmed. 2016;26:A10.

7. Crevenna R. From neuromuscular electrical stimulation and biofeedback-assisted exercise up to triathlon competitions-Regular physical activity for cancer patients in Austria. Eur Rev Aging Phys Act. 2013;10(1):53-5.

8. Mehnert A. Rückkehr zur Arbeit bei Patienten mit einer Krebserkrankung. Forum. 2011;26:23-6.

9. Peteet JR. Cancer and the meaning of work. Gen Hosp Psychiatry. 2000;22:200-5.

10. World Health Organization-International Agency for Research on Cancer.. Globocan. 2018. http://gco.iarc.fr/ today/online-analysis-table $\mathrm{v}=2018 \&$ mode $=$ population \& mode_population $=$ continents $\&$ population $=900 \&$ populations $=900 \& k e y=a s r \& s e x=0 \&$ cance 2000 . Accessed 17 Oct 2018.

11. Mehnert A. Employment and work-related issues in cancer survivors. Crit Rev Oncol Hematol. 2011;77(2):109-30.

12. Hutchison N, Deval N, Rabusch S, Rich H, Kelley T, Flinn $\mathrm{N}$, et al. Physical therapy based exercise protocol for cancer patients: Evaluating outcomes for cardiopulmonary performance and cancer-related fatigue. PM R. 2019; https://doi.org/10.1002/pmrj.12128.

13. ZengY, Huang M, ChengASK, Zhou Y, So WK. Meta-analysis of the effects of exercise intervention on quality of life in breast cancer survivors. Breast Cancer. 2014;21:262-74.

14. Hayes SC, Steele ML, Spence RR. Exercise following breast cancer: Exploratory survival analyses of two randomised, controlled trials. Breast Cancer Res Treat. 2018;167(2):505-14. https://doi.org/10.1007/s10549-0174541-9.

15. Rechtsinformationssystem des Bundes (RIS). 30. Bundesgesetz: Wiedereingliederungsteilzeitgesetz. 2017. https:// www.ris.bka.gv.at/Dokumente/BgblAuth/BGBLA_2017 I_30/BGBLA_2017_I_30.pdfsig. Accessed 17 Nov 2018, Bundesgesetzblatt für die Republik Österreich. Jahrgang 2017, Ausgegeben am 18. Jänner 2017, Teil I. NR: GPXXV RV 1362 AB 1440 S. 158. BR:AB 9680 S. 862.

16. Crevenna R. Value of Physical Modalities in Return to Work of Cancer Survivors-Results of an Expert Survey. Universitätslehrgang „MSc in Arbeits- und Organisationsmedizin“, Medical University of Graz; 2019.
17. Kennedy F, Haslam C, Munir F, Pryce J. Returning to work following cancer: A qualitative exploratory study into the experience of returning to work following cancer. Eur J Cancer Care (engl). 2007;16(1):17-25.

18. DuijtsSF, KiefferJM, van MuijenP, van derBeekAJ. Sustained employability and health-related quality of life in cancer survivors up to four years after diagnosis. Acta Oncol. 2017;56(2):174-82.

19. de Boer AG, Taskila T, Ojajarvi A, van Dijk FJ, Verbeek JH. Cancer survivors and unemployment: A meta-analysis and meta-regression. JAMA. 2009;301(7):753-62.

20. Institut national du cancer. Life two years after a cancer diagnosis: From disclosure to after cancer. 2019. http:// www.e-cancer.fr/Expertises-et-publications/Cataloguedes-publications/La-vie-deux-ans-apres-un-diagnosticde-cancer-De-l-annonce-a-l-apres-cancer. Accessed 19 Mar2018.

21. Roelen CA, Koopmans PC, van Rhenen W, Grootho JW, van der Klink JJ, Bultmann U. Trends in return to work of breast cancer survivors. Breast Cancer Res Treat. 2011;128(1):237-42.

22. Goss C, Leverment IM, de Bono AM. Breast cancer and work outcomes in health care workers. Occup Med. 2014;64(8):635-7.

23. Murray K, Lam KBH, McLoughlin D, Sadhra SS. Factors in removing job restrictions for cancer survivors in the United Kingdom Royal Air Force. J Occup Rehabil. 2018; https:// doi.org/10.1007/s10926-018-9758-x.

24. BlinderV, PatilS, EberleC, Griggs J, Maly RC. Earlypredictors of not returning to work in low-income breast cancer survivors: A 5-year longi-tudinal study. Breast Cancer Res Treat. 2013;140(2):407-16.

25. Mujahid MS, Janz NK, Hawley ST, Griggs JJ, Hamilton AS, Graff J. Racial/ethnic differences in job loss for women with breast cancer. JCancer Surviv. 2010;5(1):102-11.

26. Carlsen K, Ewertz M, Dalton SO, Badsberg JH, Osler M. Unemployment among breast cancer survivors. Scand J Public Health. 2014;42(3):319-28.

27. Fassier JB, Lamort-Bouché M, Broc G, Guittard L, Péron J, Rouat $\mathrm{S}$, et al. Developing a return to work intervention for breast cancer survivors with the intervention mapping protocol: Challenges and opportunities of the needs assessment. Front Public Health. 2018;6:35.

28. Ho PJ, Hartman M, GernaatSAM, CookAR, LeeSC, Hupkens $\mathrm{L}$, et al. Associations between workability and patientreported physical, psychological and social outcomes in breast cancer survivors: A cross-sectional study. Support Care Cancer. 2018;26(8):2815-24.https://doi.org/10.1007/ s00520-018-4132-2.

29. Brendbekken R, Vaktskjold A, Harris A, Tangen T. Predictors of return-to-work in patients with chronic musculoskeletal pain: A randomized clinical trial. J Rehabil Med. 2018;50(2):193-9.

30. Neubauer M, Schoberwalter D, CenikF, Keilani M, Crevenna R. Lymphedema and employability-Review and results of a survey of Austrian experts. Wien Klin Wochenschr. 2017;129(5/6):186-91.

31. Cenik F, Keilani M, Galid A, Crevenna R. First exercise group for Turkish breast cancer patients in Vienna-A pilot project to include Turkish migrants. Disabil Rehabil. 2019;26:1-6. https://doi.org/10.1080/09638288.2018.1514666.

32. Crevenna R. Aspects of cancer rehabilitation: An Austrian perspective. Disabil Rehabil. 2019;27:1.https://doi.org/10. $1080 / 09638288.2018 .1522554$. 
33. Hasenoehrl T, Keilani M, Palma S, Crevenna R. Resistance exerciseand breast cancer related lymphedema-Asystematic review update. Disabil Rehabil. 2019;13:1-10. https:/ / doi.org/10.1080/09638288.2018.1514663.

34. Palma S, Keilani M, Hasenoehrl T, Crevenna R. Impact of supportive therapy modalities on heart rate variability in cancer patients-A systematic review. Disabil Rehabil. 2018;4:1-8. https://doi.org/10.1080/09638288.2018. 1514664.

Publisher's Note Springer Nature remains neutral with regard to jurisdictional claims in published maps and institutional affiliations. 